\title{
Post Drill Pore Pressure Prediction for Geo-hazard Assessment of Offset Wells in Hamoru Field
}

\author{
A. Ogbamikhumi*, O. M. Hamid-Osazuwa, E. A. Imoru \\ Department of Geology, University of Benin, Nigeria.
}

ABSTRACT: Understanding the distribution and variation of subsurface formation pressure is key to preventing geohazards associated with drilling activities such as kicks and blow out. To assess and prevent such risk in drilling offset wells in the Hamoru field, prediction of pore pressure was done to understand the pressure regime of the field using well logs in the absence of seismic data. Two commonly used methods for formation pressure prediction; Bower's and Eaton's methods were adopted to predict pore pressure and determine the better of the two methods that will be more suitable for the field. The cross-plot of $\mathrm{Vp}$ against density disclosed that compaction disequilibrium is the prevalent overpressure mechanism. The prediction of Pore pressure with Eaton's method gave results comparable to the acquired pressure in the field, typical of what is expected when compaction disequilibrium is the dominant overpressure mechanism. Since the result of Bower's method over estimated formation pressure, Eaton's method appears to be the better choice for predicting the formation pore pressure in the field. Analysis of the predicted pore pressure reveals the onset of overpressure at depth of $2.44 \mathrm{~km}$. The formation pressure gradient ranges from 10.4 $\mathrm{kPa} / \mathrm{m}$ to $15.2 \mathrm{kPa} / \mathrm{m}$ interpreted as mild to moderately over pressure.

KEYWORDS: Geohazard, over-pressure, Eaton's method, Bower's method, normal compaction trend

[Received Aug. 2, 2019, Revised Jan. 31, 2020, Accepted March 26, 2020]

Print ISSN: 0189-9546 | Online ISSN: 2437-2110

\section{INTRODUCTION}

Formation pore pressure consideration is vital for drilling plan, geo-mechanical and geological evaluation to prevent some geological hazards (Jincai, 2011). In an over-pressured region such as the Niger Delta, adequate understanding of the pore pressure system is critical for economic and safe drilling operations devoid of drilling hazards like fluid influx, pressure kicks and blow out .

The fluid pressure in rock pore spaces is described as pore pressure. It varies from normal or hydrostatic pressure; to critical overpressure i.e. when the formation pressure greatly exceed the regional hydrostatic pressure. Overpressures can result from several causes, such as generation of hydrocarbon, disequilibrium compaction (under-compaction), cracking of gas, aqua thermal expansion, alterations of mineral (e.g., illitization), hydrocarbon buoyancy, tectonic compression, and hydraulic heads (Gutierrez et al., 2006; Swarbrick and Osborne, 1998).

Prediction of pore pressure can either be pre-drill or postdrill. Most predrill prediction is seismic based, while post drill can be done by direct measurement or from well log data. Prediction of formation pore-pressure obtained from shale properties acquired from wire line log were probably first attempted by Hottmann and Johnson (1965). They indicated that as pore fluid is expelled, there is a reduction in porosity as depth increases with sediments compact normally. If the rate of sedimentation is very high, compaction disequilibrium occurs which may lead to overpressure build up (Osborne and Swarbrick, 1997; Mouchet and Mitchell, 1989).

Cases of overpressure and several drilling hazards such as blowouts, lost wells and mud losses have also been recounted in some parts of the Niger Delta where certain wells have penetrated deep zones of overpressure. (Opara et al., 2013; Nwozor et al., 2013).

Well logs that serves as indicator of formation pore pressure like P-sonic, formation density, resistivity and porosity obtained from a deep well were used to calculate the formation pore pressure in the study field to understand the pressure regime of any intended offset wells in the field so as to prevent drilling hazards. The study field is situated in the Niger Delta Basin. The Niger Delta Basin is a key geological feature of substantial exploration and production of petroleum in Nigeria, and it ranks amongst the most prolific petroleum producing deltas in the worlds. The delta is located in the Gulf of Guinea, West Africa. The Niger Delta geology has been studied in detailed by several workers (Reyment, 1965; Short and Stauble, 1967; Murat, 1972; Doust and Omatsola, 1990, Morley et al., 1998; Adeogba et al., 2005; Corredor et al., 2005).

The Basin comprises of three major formation namely (sequentially from top to base); the sands of the Benin Formation, the intercalated Agbada Formation described as a deltaic facies and the marine shales of the Akata Formation. The shale of the Akata formation are significantly over 
pressured and are believed to be the main hydrocarbon source rock.

\section{MATERIALS AND METHODS}

The effective stress law postulated by Terzaghi's and Biot's is the major theory for formation Pore pressure prediction across the world (Biot, 1941; Terzaghi et al., 1996). The theory pointed out that formation pore pressure is dependent on the overburden or total stress and effective stress. Pore pressure, total stress, and the effective vertical stress are expressed in equation 1 .

$$
\rho=(\sigma \mathrm{v}-\sigma \mathrm{e}) / \alpha
$$

Where; $\rho$ is the pore pressure of the formation; $\sigma \mathrm{V}$ is the total or overburden stress; $\sigma e$ is the vertical effective stress; $\alpha$ is the coefficient of Biot effective stress

Several fundamental equations for well log based prediction of formation pore pressure have been presented based on $\mathrm{P}$-sonic $\log$, resistivity $\log$, and other well $\log$ data. The adopted techniques for this research are the two commonly used Bower's and Eaton's methods.

Eaton (1975) estimated formation pressure by comparing effective stress of a formation with that of a normally consolidated formation, and the measured velocity with velocity of a normally consolidated formation. He presented an equation for formation pore pressure gradient in younger sedimentary basins where under-compaction is the prevalent cause of overpressure, demonstrated by Lang et al., (2011). Its application is limited in geologically complicated area since it overlooks unloading effects.

Bower (1995) technique applies the P-sonic velocity and some empirically derived parameters to compute formation pressures. To determine the formation pore pressure, the difference between the vertical effective stress and the overburden stress is calculated. This technique can be adopted to estimate pore pressures that result either from disequilibrium compaction or due to other secondary mechanism. Bowers' method however, overestimates pore pressure when the formation is poorly-consolidated or under-compacted, since the velocity of the formation is very slow (Jincai , 2011).

The well data available for this study was obtained from Shell Petroleum Development Company (SPDC). They include RFT (Repeated Formation Tester) pressure data within interval of $2.93 \mathrm{~km}$ and $3.41 \mathrm{~km}$, well $\log$ data such as Resistivity $\log$, Gamma Ray log, Density log, P- Sonic and Caliper Logs (Figure 1).

ROKDOC interpretation software was used for data interpretation after the sourced data have initially been subjected to quality control checks such as depth reconciliation, filtering and de-spiking to improve the quality of the data.

Parameters estimated for the prediction process include Shale Volume and shale trend, Normal Compaction Trend (NCT), Overburden Stress and Hydrostatic pressure.

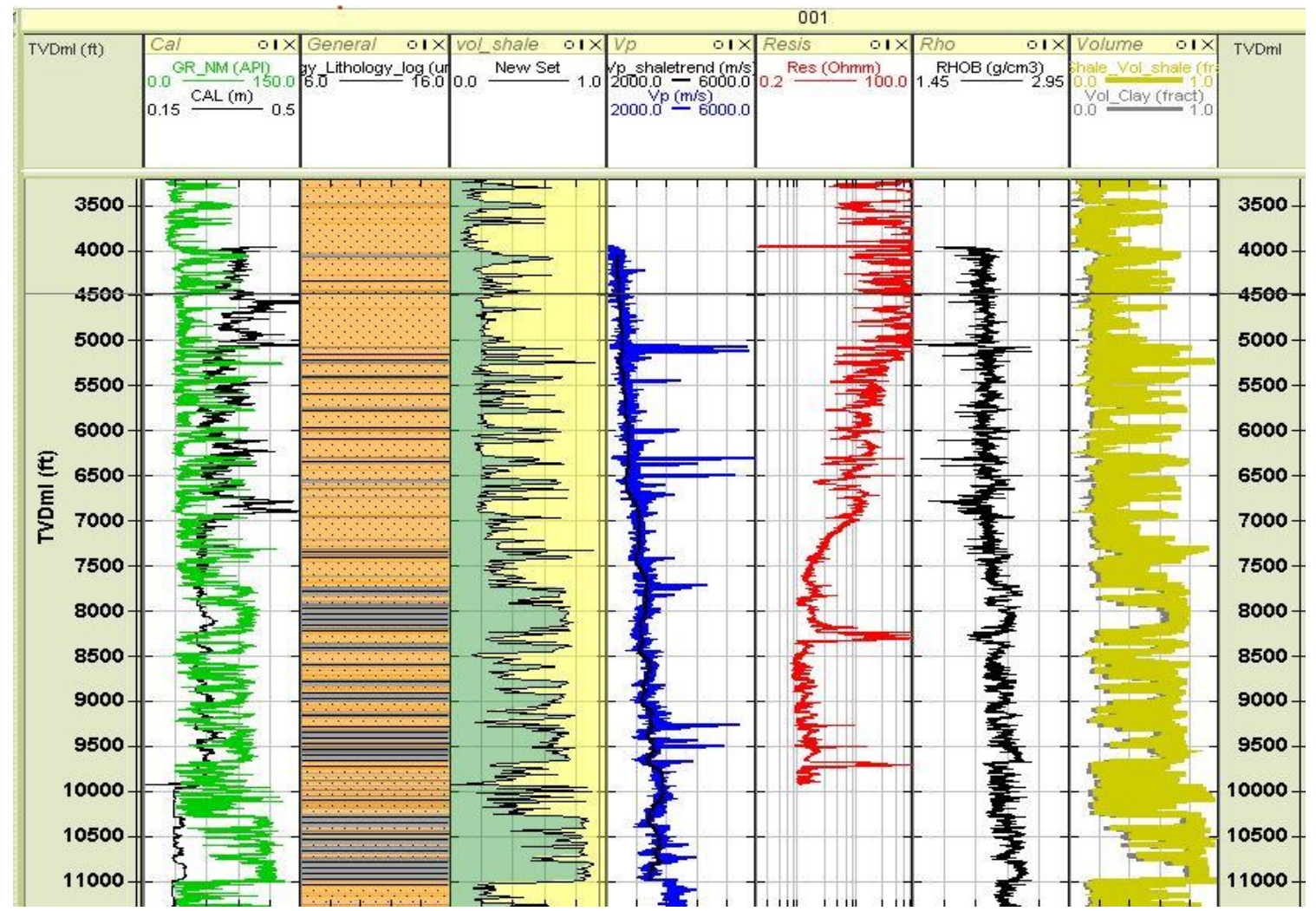

Figure 1: Display of the available and generated logs on the log view of the ROCDOK software. 


\section{RESULTS AND DISCUSSION}

Over pressure can result by two major mechanisms: disequilibrium compaction mechanism; which as a result of rapid sediment loading unaccompanied by equally rapid dewatering and compaction. (Swarbrick and Osborne, 1998) and Secondary mechanisms of overpressure that post-date the normal sediment loading mechanism that occur as depth of burial increases (Lahann and Swarbrick, 2011; Nadeau 2011). The mechanism of overpressure prevalent in the study field was determined by using a plot of Vp vs density (Rho) colour coded with depth as shown in Figure 2. The plot reveals an increase in density that results to a corresponding increase in velocity with the deepest interval assigned the highest density and velocity values, typical of what is expected when compaction disequilibrium is the mechanism responsible for the overpressures (Hoesni, 2004).

\section{A. Normal Compaction Trend}

The shale volume computed from Gamma ray log expressed as a percentage or decimal fraction is called V-shale (Volume of shale). The computed V-shale is displayed in the second tract of figure 3. Since abnormal pressure build up is common in shale, a shale cut-off was applied to eradicate the velocity within the sand interval. This was important to get a good fit of the shale trend within the cleanest shale in the well for normal compaction trend generation (Figure 5).

The Normal Compaction Trend (NCT) represents the best fit line trend of the measured velocity across the transition zone in the low permeable beds (Shaker, 2007).

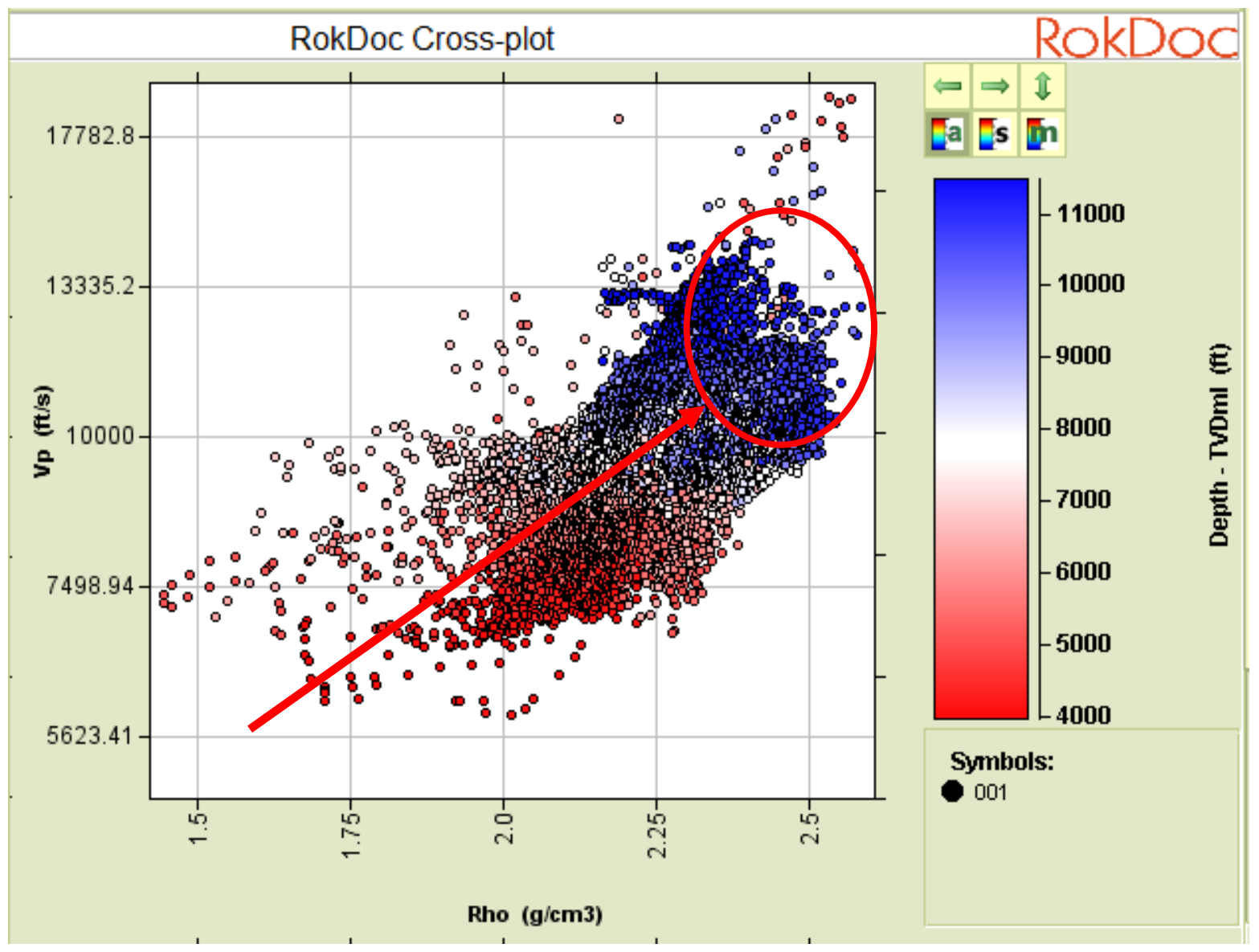

Figure 2: Plot of Vp vs Density (Rho) colour coded with depth for mechanism of over pressure determination. 


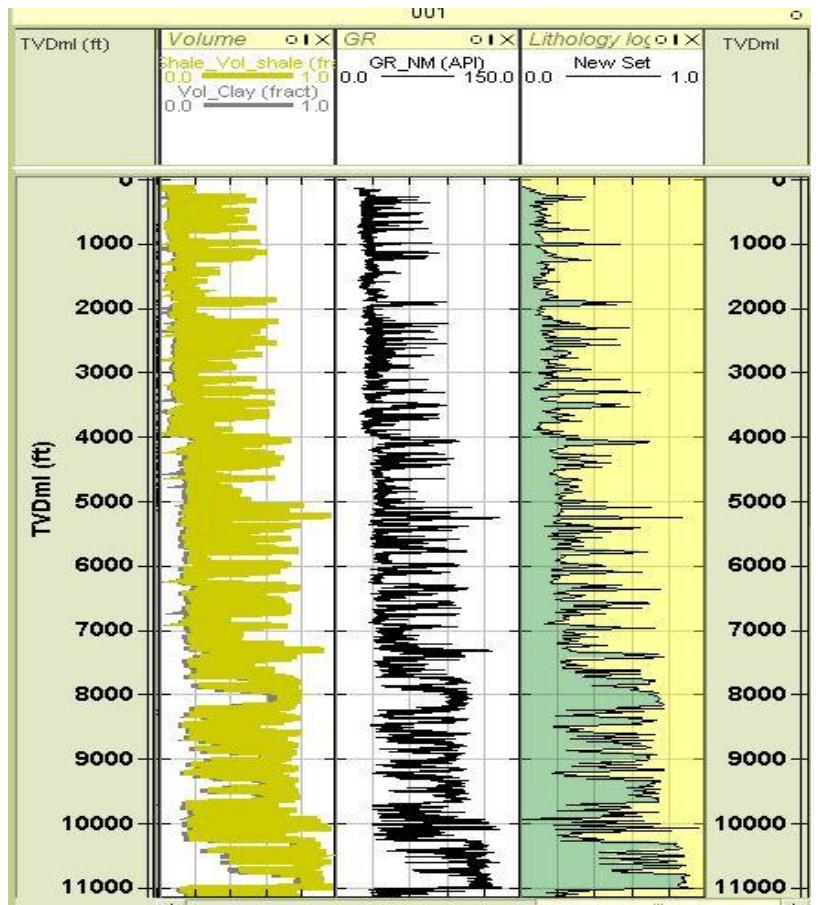

Figure 3: Display of the V-shale log in the second tract generated from Gamma ray log.

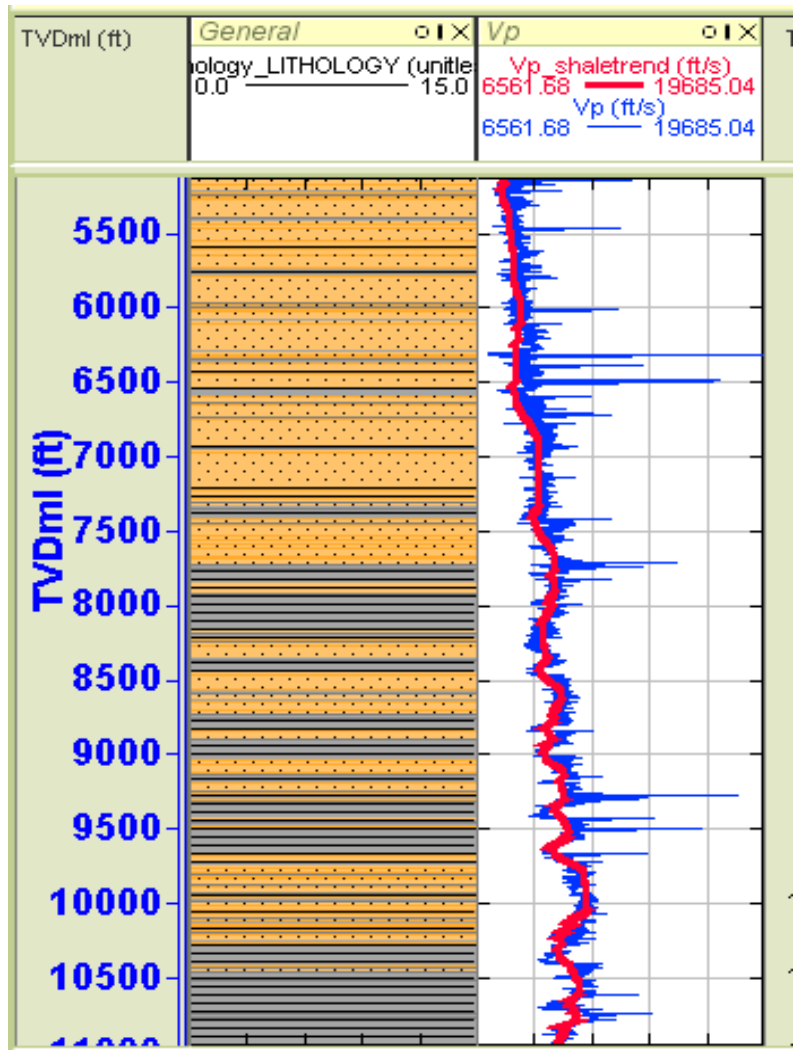

Figure 4: Display of the lithology log and Vp- shale trend.
A trend fit to the sonic velocity in figure 5 shows a noticeable compaction gradient that rise at high rate within the shallow depth interval and at a low rate at greater depth. The sediments compact normally until a depth of about $2.44 \mathrm{~km}$ (TVD) as indicated by the arrow, which mark the onset of overpressure in the well.

\section{B. Overburden Stress}

Overburden or lithostatic pressure is the pressure or stress of the overlying material weight imposed on a layer of rock. It is one of the major parameters required for pore pressure prediction using the Terzaghi's equation in equation1. It was computed using the cumulative bulk density weight above the depth of interest from the bulk density log. The computed overburden gradient is presented in Figure 6. The red line represents the overburden gradient line through the displayed density log point. This line is compared to the line of fixed gradient of $22.6 \mathrm{kPa} / \mathrm{m}$ to the right.

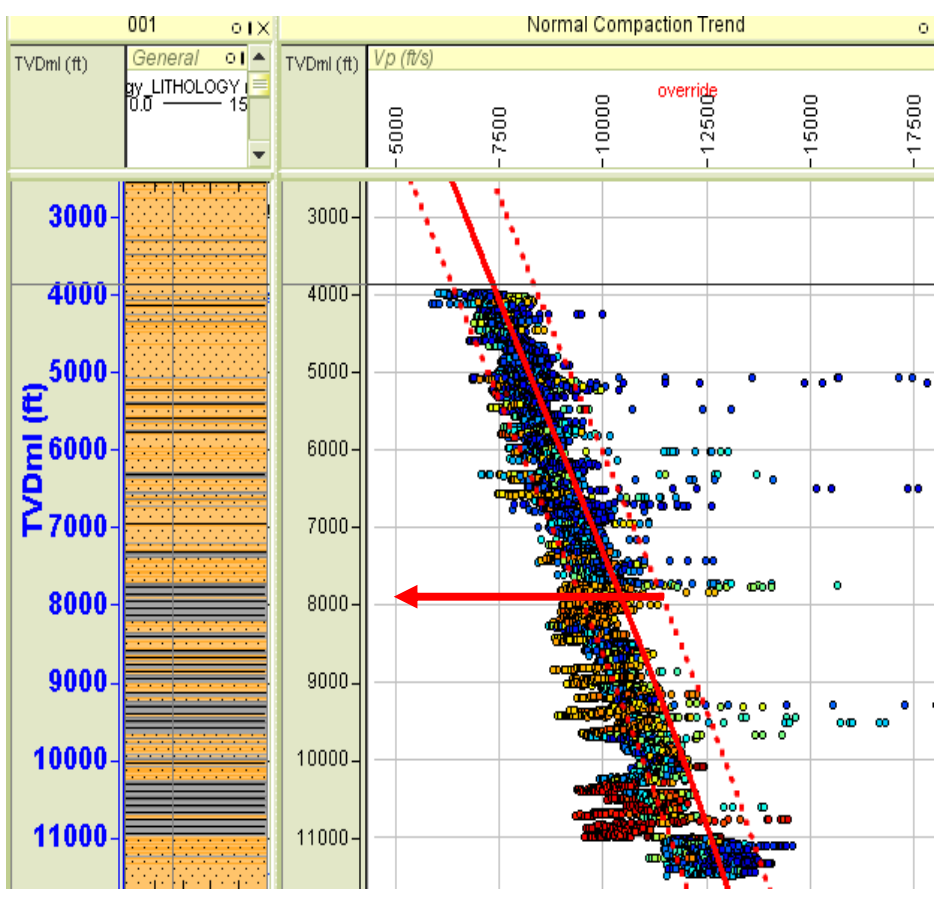

Figure 5: Normal Compaction trend indicating onset of overpressure. 


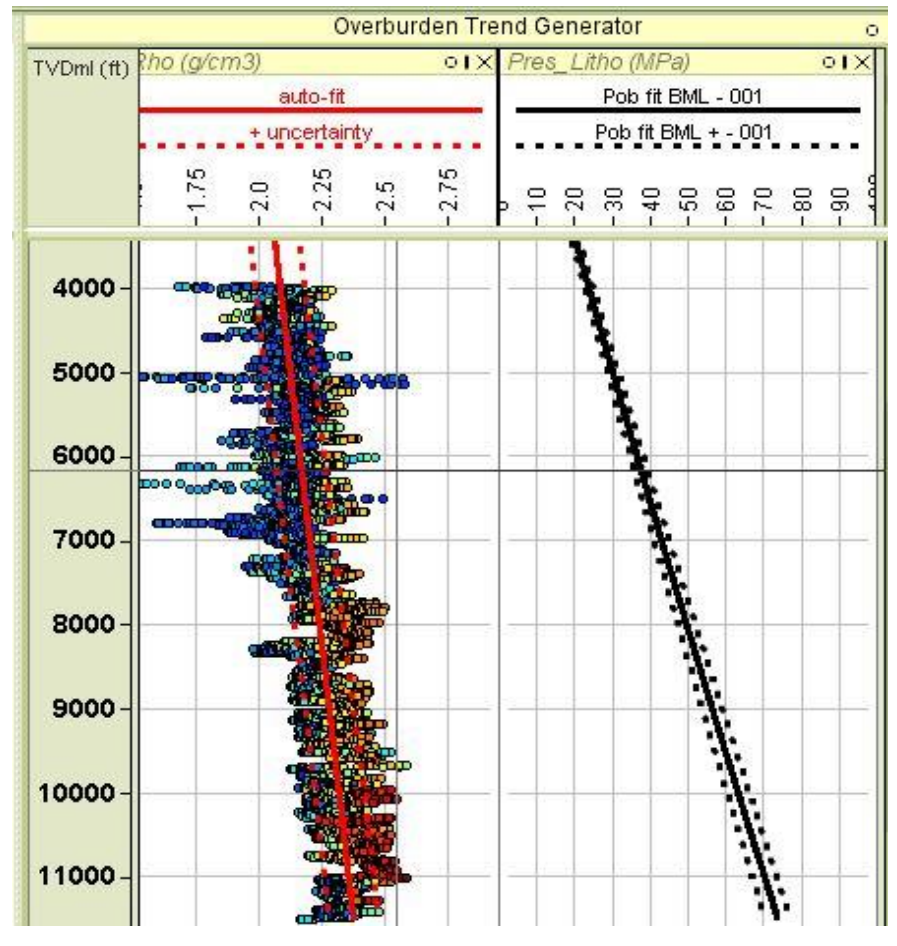

Figure 6: Overburden trend generated from the density log.

\section{Computation of Hydrostatic Stress}

Hydrostatic pressure is the pressure that acts on a given column of fluid at a particular depth. The value varies between $9.73 \mathrm{kPa} / \mathrm{m}$ and $10.86 \mathrm{kPa} / \mathrm{m}$ depending on the salinity of the formation water (Krusi, 1994) and the depth of extrapolation. The hydrostatic pressure gradient $(\mathrm{Pg})$ in $\mathrm{psi} / \mathrm{ft}$, was computed using the relation in eqn (2) at all depth points and it is also displayed in Figure 7.

$\mathrm{Pg}=0.433 \mathrm{x}$ fluid density (in slug/ft 3 )

Overpressure is said to occur when the formation pressure exceeds the hydrostatic baseline.

\section{Prediction of Pore Pressure}

The Eaton's and Bower's methods were both adopted for the prediction of the formation pore pressure, to establish the technique that will give similar results as the acquired RFT pressure data which will be adopted for pore pressure prediction for any offset wells in the field. The Eaton's method relates effective stress in a well with that of a normally consolidated formation, and the velocity of a normally consolidated formation with the measured velocity to predict formation pore pressure. The method adopts the vertical effective stress generated from a computed normal compaction trend, with the assumption that the formations are basically mechanically compacted, the sediments are at maximum effective stress and the lithology is thick shale. Computation of lithology and volume of shale log that applied shale cut-off ensures that Vp-trend estimated to generate the normal compaction trend is restricted within the thick shales. The pore pressure was computed using the Terzaghi equation in equation in equation 1. The result is displayed in Figure 7).

The Bower's method demonstrated the error common with linking pore pressure to the deviation of velocity from computed compaction trend (Bower, 1995). The observed deviation could be as a result of complex variation in lithology that could cause a significant change in velocity that is not essentially related with pore pressure. To correct this anomaly, Bower proposed a method that calculates effective stress directly from velocity without establishing the compaction trend, which is deducted from overburden stress to get formation pore pressure using the Terzaghi equation. The predicted pore pressure using this technique is presented in Figure 7.

This method most times account for the inadequacies associated with pore pressure prediction when unloading is involved in the generation of overpressure, but tend to overestimate pore pressure when compaction disequilibrium is the more prevalent mechanism of over pressure, and this is mostly seen in shallow, unconsolidated sediments. This situation was observed in figure 7 . Comparing the acquired pressure data with the predictions done with both methods, it is observed that there exist strong similarities between the measured pressure and pressures predicted with Eaton's method, confirming that Eaton's model will give better results for prediction of an off-set well pressure regime. This was expected as seen in the result obtained from the cross plot to determine overpressure mechanism in figure 2, which depicts disequilibrium compaction rather than unloading as the prevalent mechanism of over pressure in the study field.

In Figure 5, normal compaction is observed at depth interval shallower than $2.44 \mathrm{~km}$, and the normal compaction trend line shows a shift at this depth to the left which is an indication of the onset of overpressure. At this depth, the pressure of the well is expected to have exceeded the hydrostatic pressure. In the Niger Delta where the study field is located, the normal average hydrostatic pressure gradient is usually $9.90 \mathrm{kPa} / \mathrm{m}$. The result showed that the field is mildly to moderately over pressured with pressure gradient of 10.46 $\mathrm{kPa} / \mathrm{m}$ to $15.25 \mathrm{kPa} / \mathrm{m}$ at depth of about $2.44 \mathrm{~km}$ (onset of over pressure) to $3.35 \mathrm{~km}$ ( Nwozor et al., 2013). 


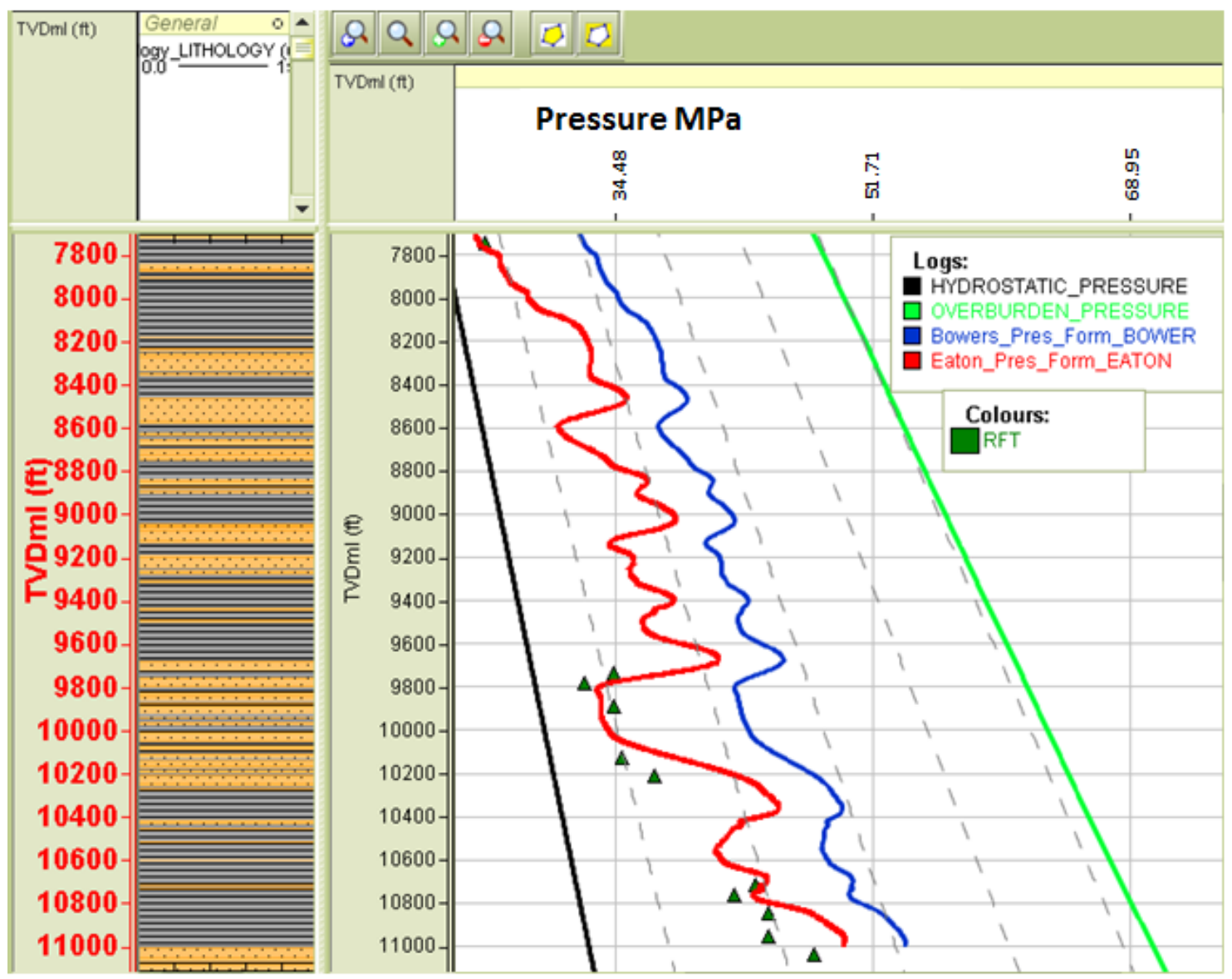

Figure 7: Results of Bower's and Eaton's pressure models superimposed on the measured pressure.

\section{CONCLUSION}

Well $\log$ data were used to predict formation pore pressure using Eaton's and Bower's method to determine the better of the two methods to adopt for pore pressure prediction in the Hamoru field in order to understand the pressure regimes of the field to prevent geo-hazards during drilling of any proposed offset wells in the field. Pore pressure prediction using Eaton's method gave results similar to the acquired pressure in the field, typical of what is expected when disequilibrium compaction is the prevalent mechanism of overpressure. Although Bower's model could also be used to estimate pore pressure that result from disequilibrium compaction, but in the study field, the method over estimated formation pressures.

Hence Eaton's method appears to be better suited for formation pore pressure estimation in Hamoru field. This study revealed that disequilibrium compaction is the main overpressure generating mechanism in the field. Analysis of the results of pore pressure prediction reveals the onset of overpressure at depth below $2.44 \mathrm{~km}$. The formation pressure gradient ranges from $10.4 \mathrm{kPa} / \mathrm{m}$ to $15.2 \mathrm{kPa} / \mathrm{m}$ making the Hamoru field a mild to moderately over pressured zone.

\section{REFERENCES}

Adeogba, A. A.; T. R. McHargue and S. A. Graham. (2005). Transient fan architecture and depositional controls from near-surface 3-D seismic data, Niger Delta continental slope. AAPG bulletin, 89(5): 627-643.

Bowers, G. L. (1995). Pore pressure estimation from velocity data: Accounting for overpressure mechanisms besides undercompaction. Society of petroleum Engineer Drilling and Completions, 10(2): 89-95.

Biot, M. A. (1941). General theory of three dimensional consolidation. Journal of applied physics, 12(2): 155-164.

Corredor, F.; J. H Shaw and F. Bilotti. (2005). Structural styles in the deep-water fold and thrust belts of the Niger Delta. AAPG Bulletin, 89(6):753-780.

Doust, H. and Omatsola, E. (1990). Niger delta, In: J. D. Edwards and P. A. Santogrossi, eds., Divergent/Passive Margin Basins, AAPG Memoir, 48: 239-248.

Eaton, B.A. (1975). The equation for geopressure prediction from well logs. In fall meeting of the Society Petroleum Engineer of AIME. Society Petroleum Engineer meeting 1975 bulleting: 50-63. 
Gutierrez, M.A.; N.R. Braunsdorf; and B.A. Couzens. (2006). Calibration and ranking of pore-pressure 755 prediction models. The leading Edge, 26:1516-1523.

Hoesni, M.J. (2004). Origins of overpressures in Malay basin and it influence on petroleum system. Unpublished Ph.D. Thesis, Durham University. England.

Hottman, C.E. and Johnson, R.K. (1965). Estimation of formation pressures from log-derived shale properties. Journal of Petroleum Technology, 17: 717-722.

Jincai, Z. (2011). Pore pressure prediction from well logs: methods, modifications, and new approaches. EarthScience Reviews, 108(1-2):50-63

Krusi, H. R. (1994). Overpressure prediction; A contribution towards safer drilling; Nigeria Association of Petroleum Explorationists Bulletin, 9:86 -91.

Lahann, R.W. and Swarbrick, R.E. (2011). Overpressure generation by load transfer following shale framework weakening due to smectite diagenesis. Geofluids, 11: 362-375.

Lang, J.; S. Li. and J. Zhang. (2011). Wellbore stability modeling and real-time surveillance for deepwater drilling to weak bedding planes and depleted reservoirs. In SPE/IADC Drilling confrence and Exhibition. SPE, 2011.

Morley, C. K.; P. Crevello and Z. H. Ahmad. (1998). Shale tectonics and deformation associated with active diapirism: the Jerudong Anticline, Brunei Darussalam. Journal of the Geological Society, 155(3): 475-490.

Mouchet, J. P. and Mitchell, A. (1989). Abnormal pressures while drilling: Origins, prediction, detection, evaluation. Edition Tchnip, (2):54-62

Murat, R.C. (1972). Stratigraphy and Palaeogeography of the Cretaceous and Lower Tertiary in Southern Nigeria. In: African Geology. Dessauvagie, F.J. and Whiteman, A.J. (eds). University of Ibadan Press, Ibadan, Nigeria.
Nadeau, P. H. (2011). The 2010 George Brown lecture Earth"s energy "Golden Zone": a synthesis from mineralogical research. Clay Minerals, 46:1-24.

Nwozor, K.K.; M.L. Omudu; B.M. Ozumba; C.J. Egbuachor; A.G. Onwuemesi and O.L. Anike. (2013). Quantitative evidence of secondary mechanism of overpressure generation: Insight from parts of Onshore Niger Delta, Nigeria. Petroleum technology development journal, 3(1): 64-83.

Opara, A.I.; K.M. Onuoha; C. Anowai; N.N. Onu and R.O. Mbah. (2013). Geopressure and trap integrity predictions from 3-D seismic data: Case Study of the Greater Ughelli Depobelt, Niger Delta. Oil and Gas Science and Technology Rev. IFP Energies nouvelles, 68(2): 383-396.

Osborne, M.J. and Swarbrick, R.E. (1997). Mechanism for generating overpressure in sedimentary basins: A revaluation. American Association of Petroleum Geologists Bulletin, 81: 1023-1041.

Reyment, R.A. (1965). Aspects of the Geology of Nigeria. University Press, Ibadan, Nigeria.

Shakar, S. (2007). Calibration of Geopressure prediction using Normal Compaction Trend: Perception and Pitfall: CSEG Recorder, 32:29-35.

Short, K.C. and Stauble, A.J. (1967). Outline of geology of Niger Delta. American Association of Petroleum Geologists Bulletin, 51: 761-779.

Swarbrick, R.E. and Osborne, M.J. (1998). Mechanisms that generate abnormal pressures: an overview. In Abnormal Pressures in Hydrocarbon Environments. American Association of Petroleum Geologists Memoir, 70: 13-34.

Terzaghi, K..; R. B. Peck and G. Mesri. (1996). Soil mechanics in engineering practice. John Wiley \& Sons Press. New York, USA. 